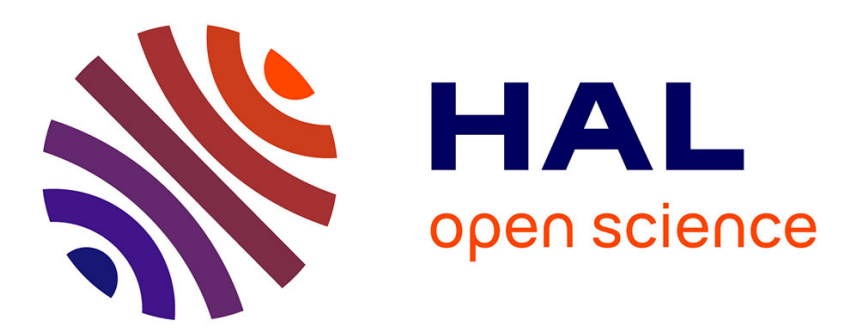

\title{
Temperature dependence of free volume distributions in polymers studied by positron lifetime spectroscopy
}

\author{
J. Krištiak, K. Krištiaková, O. Šauša, P. Bandžuch, J. Bartoš
}

\section{To cite this version:}

J. Krištiak, K. Krištiaková, O. Šauša, P. Bandžuch, J. Bartoš. Temperature dependence of free volume distributions in polymers studied by positron lifetime spectroscopy. Journal de Physique IV Proceedings, 1993, 03 (C4), pp.C4-265-C4-270. 10.1051/jp4:1993441 . jpa-00251484

\section{HAL Id: jpa-00251484 https://hal.science/jpa-00251484}

Submitted on 1 Jan 1993

HAL is a multi-disciplinary open access archive for the deposit and dissemination of scientific research documents, whether they are published or not. The documents may come from teaching and research institutions in France or abroad, or from public or private research centers.
L'archive ouverte pluridisciplinaire HAL, est destinée au dépôt et à la diffusion de documents scientifiques de niveau recherche, publiés ou non, émanant des établissements d'enseignement et de recherche français ou étrangers, des laboratoires publics ou privés. 


\title{
Temperature dependence of free volume distributions in polymers studied by positron lifetime spectroscopy
}

\author{
J. KRIŠTIAK, K. KRIŠTLAKOVÁ, O. ŠAUŠA, P. BANDŽUCH and J. BARTOŠ* \\ Institute of Physics, Slovak Academy of Sciences, 84228 Bratislava, Slovakia \\ * Polymer Institute, SAS, 84228 Bratislava, Slovakia
}

\begin{abstract}
The temperature dependence of mean ortho-positronium lifetime $\left(\bar{\tau}_{3}\right)$ and intensity $\left(\mathrm{I}_{3}\right)$ was measured in the range between 60 and $293 \mathrm{~K}$ for polycarbonate and polyoxymethylene samples. The values of $\bar{\tau}_{3}$ and $I_{3}$ are a constant below $\mathrm{T}=127 \mathrm{~K}$. Above this temperature the $\bar{\tau}_{3}$ as well as $\mathrm{I}_{3}$ are a linear function of $\mathrm{T}$. Annihilation lifetime measurements have also been performed to deduce the free-volume hole distributions in the polycarbonate and polyoxymethylene polymer samples at temperature of 70 and $293 \mathrm{~K}$. Lifetime spectra were analysed using the Laplace transform and the hole volume distributions are determined from the results of o-Ps lifetime distributions using the particle in a spherical box theory. The free-volume hole radii of polycarbonate at $293 \mathrm{~K}$ are distributed between 2.1 and $3.9 \AA$ with a maximum at $(2.83 \pm 0.02) \AA$. Free volumes spread out between 40 and $230 \AA^{3}$ with a maximum at $(92 \pm 2) \AA^{3}$. In the case of polyoxymethylene, the free volume hole radii at $293 \mathrm{~K}$ are peaked at $(3.10 \pm 0.07) \AA$ inside $\left(2.0\right.$ - 4.6) $\AA$ interval. Free volumes are distributed between 35 and $350 \AA^{3}$ with a maximum at $(125 \pm 8) \AA^{3}$. At $\sim 75 \mathrm{~K}$ the distributions are quite different. They are narrower and shifted to lower values of $R(V)$. In the case of polyoxymethylene, mean value of radius is $(2.06 \pm 0.02) \AA$ and mean free volume is $(35 \pm 2) \AA^{3}$. In the case of polycarbonate, mean radius is $(2.5 \pm 0.05) \AA$ and the mean free volume is $(70 \pm 4) \AA^{3}$.
\end{abstract}

\section{Introduction}

It becomes more clear that the concept of free volume [1] is very useful for understanding of macroscopic physical properties of the polymers. The size and concentration of free volume holes in polymers determine e.g. polymer chain dynamics, diffusion processes and rheological properties. The temperature dependence of the hole free volume, especially the change of it through the glass transition region and below $\mathrm{T}_{\mathrm{g}}$ is very important to describe the physical ageing of polymers.

In spite of considerable effort in the theoretical development of the free volume notion, only limited experimental data on free volume in polymers have been reported $[2,3]$. One of the potentially most powerful technique for determining free volume sizes in non-conductive materials is positron annihilation lifetime spectroscopy (PALS). 
PALS is capable of determining the free volume hole properties directly. This capability arises from the fact that positronium (bound state of positron and electron, Ps) is preferentially localized in regions of free volume of atomic scale. The primary mechanism of annihilation of triplet positronium (o-Ps) is by pick-off with electrons of the bulk medium. Thus the life-time of o-Ps $\left(\tau_{3} \leq 142 \mathrm{nsec}\right)$ is sensitive to its local molecular environment. Generally, the lifetime of o-Ps is determined by an overlap integral between the positron and the electron densities in the hole. One expects the o-Ps lifetime to correlate directly with the hole size because a larger hole, which contains a lower mean electron density, results in a longer Ps life-time. A number of semiempirical correlations between the free volume size and the annihilation rate have been developed [4,5]. All of them are based on a simple quantum mechanical model where o-Ps resides in a spherical well having an infinite potential barrier of radius $R_{0}$ with a homogeneous electron layer in the region $R<r<R_{0}\left(R_{0}=R+\Delta R\right)$. Such a model predicts a connection between $\tau_{3}$ and the free volume hole size. Using this semiempirical model and a value $\Delta \mathrm{R}=1.656 \AA$ from fitting the measured $\tau_{3}$ of cavities with known sizes, one can determine the average absolute size of free volume holes from the relation

$$
1 / \tau_{3}=2\left[1-\mathrm{R} / \mathrm{R}_{0}+(1 / 2 \pi) \sin \left(2 \pi \mathrm{R} / \mathrm{R}_{0}\right)\right]
$$

where $\tau_{3}$ and $\mathrm{R}$ are expressed in nanoseconds and Ångströms, respectively. Until recently, the analysis of positron decay curves into 3- or 4-components limited such analyses to the determination of average free-volume radius by converting the measured o-Ps lifetime $\left(\tau_{3}\right.$ or $\left.\tau_{4}\right)$ according to eq.1. R. B. Gregory [3] has developed a new technique for the analysis of positron annihilation lifetime data using a Laplace transform method to obtain a continuous distribution of o-Ps lifetimes from PALS spectra.

In the present work we describe the application of Gregory's algorithm [6] to derive free-volume radius and volume distributions in polycarbonate and polyoxymethylene polymers at different temperatures.

\section{Experimental Procedures}

Disks of $10-\mathrm{mm}$ diameter were machined from polycarbonate and polyoxymethylene sheets of $\sim 5 \mathrm{~mm}$ thickness. The samples were prepared at the Polymer Institute. The positron source ${ }^{22} \mathrm{NaCl}$ was deposited in an envelope of KAPTON foils $(8 \mu \mathrm{m}$ thick) and then sandwiched in between two identical pieces of the samples. This sandwich was completely enclosed in a copper sample holder at the end of the cold finger of a close-cycle helium gas refrigerator. Each selected temperature was kept constant within $\pm 0.5 \mathrm{~K}$ during data acquisition. The entire source-sample assembly was placed in vacuum. The following sequence of measurements was carried out:

a) The measurements were performed at $293 \mathrm{~K}$ on samples immediately after source installation.

b) Next the temperature was lowered to $\sim 50 \mathrm{~K}$ and then the temperature was raised to $293 \mathrm{~K}$ in steps of $10 \mathrm{~K}$ and lifetime spectra were obtained at each temperature. At least two sets of such measurements have been performed.

c) Approximately 20 hour measurements have been carried out at 75 and $293 \mathrm{~K}$, respectively. 
During periods of constant temperature lifetime spectra were collected on a PC-multichannel analyser within 60 minutes. We employed a lifetime spectrometer with plastic scintillators coupled to Philips XP2020 photomultipliers. ORTEC 583 constant fraction discriminators were used for selecting the energy and providing timing signals to a time-to-amplitude converter. With an appropriate window setting of both CDF's $(511 \mathrm{keV}$ and $1275 \mathrm{keV}$ ) spectra with 320 ps (FWHM) time resolution were obtained. A model-independent estimate of the instrument resolution function was obtained from the decay curves of ${ }^{207} \mathrm{Bi}$ isotope with a single lifetime of $182 \mathrm{ps}$. These ${ }^{207} \mathrm{Bi}$ data have been used in conventional data analysis (fit of several exponentials) as well as in the numerical Laplace transform method.

In conventional analysis the PATFIT-88 program [7] was employed. Source correction terms were subtracted from each spectrum. The resolution function was approximated as a sum of three Gaussians. Three- as well as four-component analyses of data were performed. Four-component analyses described the polyoxymethylene data very well, but the use of four components for polycarbonate gives an error for the intensity of the third component ( $\sim 900 \mathrm{ps}$ ) comparable to the intensity itself.

\section{Results}

In Fig. 1 the results of measurements of the o-Ps decay as a function of temperature in the amorphous polycarbonate material are displayed. Data are well described by two lines with an intercept at $\mathrm{T}_{\mathrm{b}}=127.3 \pm 21.0 \mathrm{~K}$. We can say that $\tau_{3}$ does not change below $\mathrm{T}_{\mathrm{b}}$.

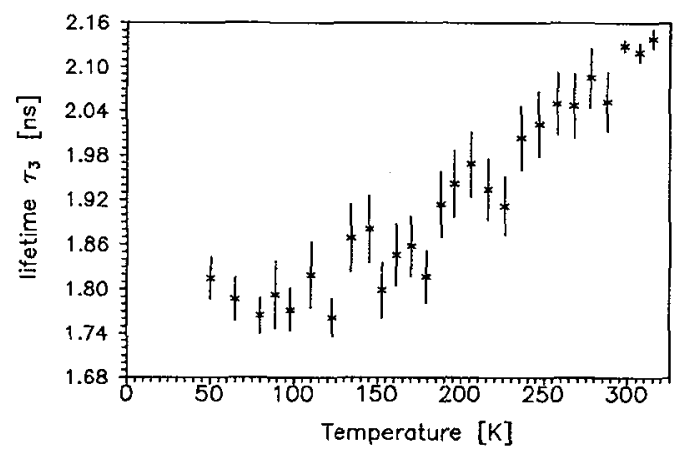

Fig.1. Temperature behaviour of o-Ps decay $\left(\tau_{3}[\mathrm{~ns}]\right)$ for amorphous polycarbonate.

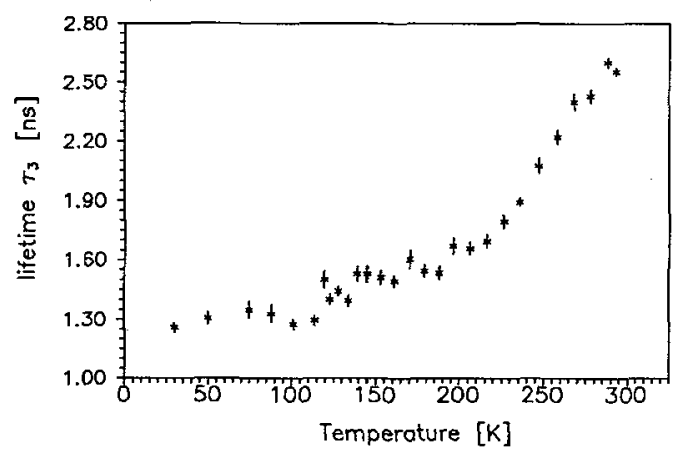

Fig.2. Temperature behaviour of o-Ps decay $\left(\tau_{3}[\mathrm{~ns}]\right)$ for semicrystalline polyoxymethylene.

The temperature behaviour of the semicrystalline polyoxymethylene (Fig. 2) is different. Below $\sim 110 \mathrm{~K} \tau_{3}$ is a constant but above this temperature the data cannot be fitted by one line only due to a structure at $\sim 160 \mathrm{~K}$. Results from the PATFIT-88 program with a free-fitting procedure for both polymers at temperatures of 75 and $293 \mathrm{~K}$ are listed in Table 1 and 2, respectively. 
Table 1. Positron lifetime results in a polycarbonate at the temperatures of 75 and $293 \mathrm{~K}$, respectively.

\begin{tabular}{rrrrrrr}
\hline $\mathrm{T}[\mathrm{K}]$ & $\tau_{1}[\mathrm{ps}]$ & $\tau_{2}[\mathrm{ps}]$ & $\tau_{3}[\mathrm{ps}]$ & $\mathrm{I}_{1}[\%]$ & $\mathrm{I}_{2}[\%]$ & $\mathrm{I}_{3}[\%]$ \\
\hline 293 & $203 \pm 6$ & $507 \pm 12$ & $2141 \pm 10$ & $36 \pm 2$ & $35 \pm 2$ & $29 \pm 1$ \\
75 & $201 \pm 10$ & $453 \pm 10$ & $1802 \pm 8$ & $31 \pm 2$ & $47 \pm 2$ & $22 \pm 1$ \\
\hline
\end{tabular}

Table 2. Positron lifetime results in a polyoxymethylene at the temperatures of 75 and $293 \mathrm{~K}$, respectively

\begin{tabular}{rrrrrrr}
\hline $\mathrm{T}[\mathrm{K}]$ & $\tau_{1}[\mathrm{ps}]$ & $\tau_{2}[\mathrm{ps}]$ & $\tau_{3}[\mathrm{ps}]$ & $\mathrm{I}_{1}[\%]$ & $\mathrm{I}_{2}[\%]$ & $\mathrm{I}_{3}[\%]$ \\
\hline 293 & $198 \pm 3$ & $509 \pm 9$ & $2550 \pm 10$ & $47 \pm 1$ & $30 \pm 1$ & $23 \pm 1$ \\
75 & $187 \pm 6$ & $439 \pm 14$ & $1334 \pm 11$ & $43 \pm 2$ & $37 \pm 2$ & $20 \pm 1$ \\
\hline
\end{tabular}

Next, we analyzed the PALS spectra taken at $293 \mathrm{~K}$ and $75 \mathrm{~K}$ as a continuous lifetime distribution using the modified CONTIN program [6,8]. Constrained, regularized least-squares solution of the Fredholm integral equation provides the positron annihilation rate probability density function $\alpha(1 / \tau)$. Only that portion of $\alpha(1 / \tau)$ describing the distribution of rates for o-Ps species has been considered in the derivation of the corresponding free-volume probability density distribution (PDF). The transformation of the annihilation rate PDF $\alpha(1 / \tau)$ to the corresponding radius $\mathrm{PDF}$ for the free-volume region in which o-Ps annihilates is obtained from eq.(1). The radius $\mathrm{PDF}$ is given by

$$
\mathrm{f}(\mathrm{R})=2 \Delta \mathrm{R}(\cos [2 \pi \mathrm{R} /(\mathrm{R}+\Delta \mathrm{R})]-1) \alpha(1 / \tau) /(\mathrm{R}+\Delta \mathrm{R})^{2}
$$

Then the fraction of positrons annihilating in cavities with radii between $R$ and $R+d R$ is $f(R) d R$. The free-volume PDF assuming a spherical cavity is

$$
g(V)=f(R) / 4 \pi R^{2}
$$

In Fig. 3 we show the results of $f(R)$ for the polycarbonate at 293 and $75 \mathrm{~K}$. The freevolume PDFs, $g(V)$, calculated according to eq.(3) for data from Fig. 3 are plotted in Fig. 4. In Fig. 5 we show $f(R)$ for the polyoxymethylene sample at 293 and $75 \mathrm{~K}$. Free volume PDFs $g(V)$ from the $f(R)$ results of Fig. 5 are displayed in Fig. 6.

Comparing the lifetime results obtained by using the CONTIN program and by the PATFIT- 88 program, we found that results of long lifetimes, $\tau_{3}$ and $\mathrm{I}_{3}$, agree with each other. There are discrepancies obtained in the results concerning the p-Ps. Moreover, we found that results of o-Ps lifetime distribution are stable and unique. Therefore, they can be correctly used to interpret the free-volume distribution in polymers. The mean values of $R$ and $V$ calculated from probability density distributions 
are given in Table 3 for polycarbonate and in Table 4 for polyoxymethylene.

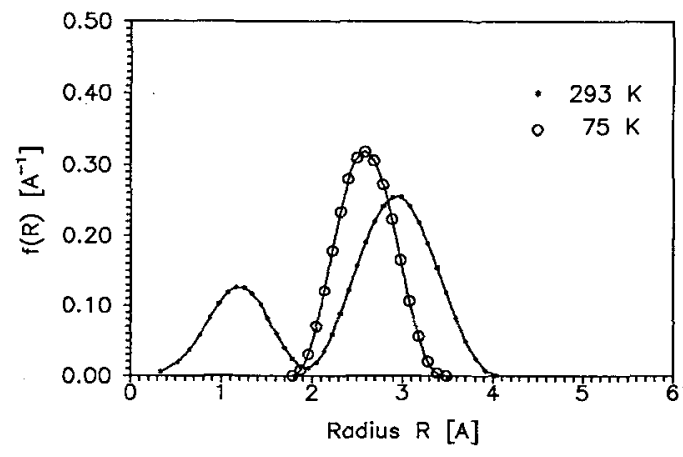

Fig.3. Hole radius distribution function $f(R)$ at temperatures $293 \mathrm{~K}$ and $75 \mathrm{~K}$ for amorphous polycarbonate.

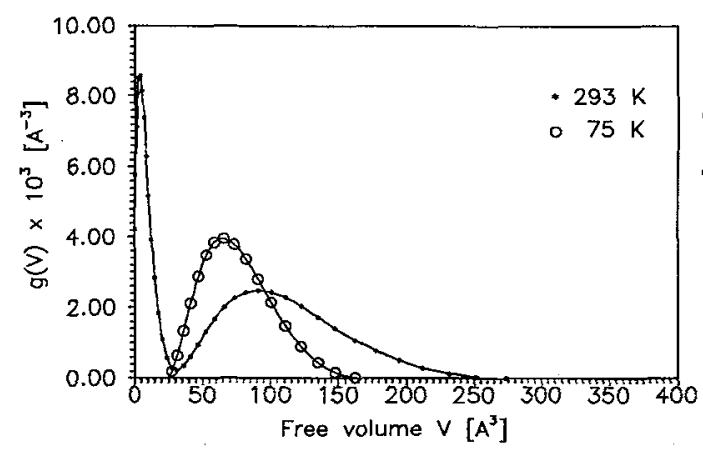

Fig.4. Distribution of free volumes $\mathrm{g}(\mathrm{V})$ at temperatures $293 \mathrm{~K}$ and $75 \mathrm{~K}$ for amorphous polycarbonate.

Table 3. Mean free volume hole radius $\tilde{\mathbf{R}}$, mean free volume $\bar{v}$ and $\sigma$-width of $f(R)$ of a polycarbonate at different temperatures

\begin{tabular}{cccc}
\hline $\mathrm{T}[\mathrm{K}]$ & $\tilde{\mathrm{R}}[\AA]$ & $\overline{\mathrm{V}}\left[\AA^{3}\right]$ & $\sigma[\AA]$ \\
\hline 293 & $2.83 \pm 0.02$ & $92.4 \pm 2.0$ & 0.94 \\
75 & $2.55 \pm 0.05$ & $69.5 \pm 4.1$ & 0.73 \\
\hline
\end{tabular}

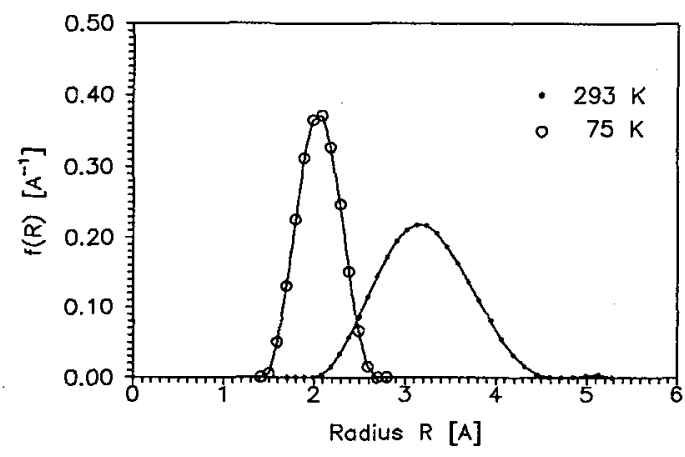

Fig.5. Hole radius distribution function $\mathrm{f}(\mathrm{R})$ at temperature $293 \mathrm{~K}$ and $75 \mathrm{~K}$ for semicrystalline polyoxymethylene.

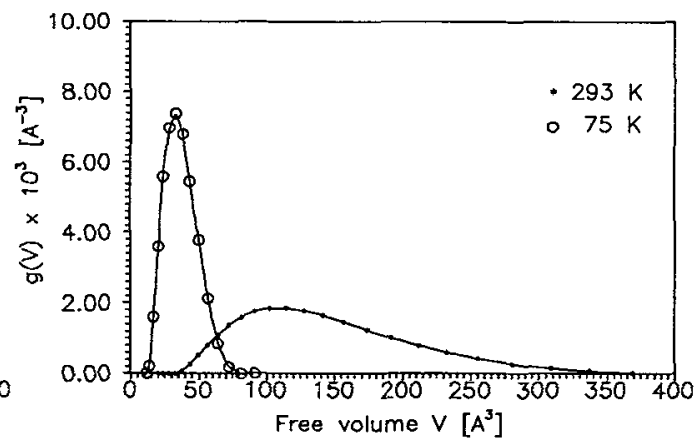

Fig.6. Distribution of free volumes $\mathrm{g}(\mathrm{V})$ at temperatures $293 \mathrm{~K}$ and $75 \mathrm{~K}$ for semicrystalline polyoxymethylene.

Table 4. Mean free volume hole radius $\tilde{\mathrm{R}}$, mean free volume $\bar{V}$ and $\sigma$-width of $f(R)$ of a polyoxymethylene at different temperatures

\begin{tabular}{cccc}
\hline $\mathrm{T}[\mathrm{K}]$ & $\overline{\mathrm{R}}[\AA]$ & $\overline{\mathrm{V}}\left[\AA^{3}\right]$ & $\sigma[\AA]$ \\
\hline 293 & $3.10 \pm 0.07$ & $124.6 \pm 8.0$ & 1.37 \\
75 & $2.06 \pm 0.02$ & $35.4 \pm 1.2$ & 0.58 \\
\hline
\end{tabular}

All errors are statistical ones. They do not include possible systematic errors arising from the analysis procedure. The hole radius distribution function $f(R)$ is symmetric and can be characterised by a full width at half - maximum $\sigma$. As intuitively expected, an increase in the temperature results in an enlargement of the free-volume holes. 
This increase of $\overline{\mathbf{R}}$ is different for an amorphous polycarbonate and semi-crystalline polyoxymethylene, i. e. $11 \%$ and $50 \%$ increase, respectively. Also, the temperature behaviour of $\sigma$ is different for polycarbonate and polyoxymethylene, the increase of $\sim 30 \%$ and $\sim 140 \%$ has been observed. Such temperature behaviour of $\overline{\mathbf{R}}(\overline{\mathbf{V}})$ can be explained by a simple thermodynamical model [9] where holes are thermally generated and a dynamical equilibrium between creation of hole and its annihilation takes place.

\section{Conclusions}

We have presented results of positron lifetime measurements in polycarbonate and polyoxymethylene carried out at different temperatures. Positron lifetime spectra were analyzed by means of the PATFIT- 88 program in a free three-component analysis and by the CONTIN program. The temperature behaviour of the free-volume hole size distribution has been deduced for an amorphous polycarbonate and a semicrystalline polyoxymethylene.

Acknowledgement. We are grateful to Dr. J. Tiňo for kindly supplying a polyoxymethylene sample and many valuable discussions. We thank Dr. S. W. Provencher and Prof. R. B. Gregory for sending us the CONTIN program. The research was supported, in part, by the Grant Agency for Science (grant no. 2/55/93).

\section{References}

/1/ DOOLITTLE, A. K., J.Appl.Phys. 22 (1971) 1471.

/2/ DENG, Q., ZANDIEHNADEM, F., JEAN, Y. C., Macromolecules 25 (1992) 1090.

/3/ GREGORY, R. B., J.Appl.Phys. 70 (1991) 4665.

/4/ TAO, S. J., J.Phys.Chem. 56 (1972) 5499.

/5/ EldRUP, M., LIGHTBODY, D., SHERWOOD, J. N., Chem.Phys. 63 (1981) 51.

/6/ GREGORY, R. B., ZHU, Y., Nucl.Instr.Meth. A290 (1990) 1172.

/7/ KIRKEGAARD, P., PEDERSEN, N. Y., ELDRUP, M., Report RIS $\varnothing$ - M - 2740.

/8/ PROVEnCHER, S. W., Comput. Phys. Comm. 27 (1982) 229.

/9/ BARTOŠ, J., KRIŠTIAK, J., to be published. 